\title{
TECNOLOGIA EDUCATIVA PARA OS CUIDADORES DE PACIENTES SUBMETIDOS A TRAQUEOSTOMIA: ESTUDO DE VALIDAÇÃO
}

\author{
EDUCATIONAL TECHNOLOGY FOR CAREGIVERS OF PATIENTS WITH TRACHEOSTOMY: \\ VALIDATION STUDY
}

\author{
Ana Cláudia Souza Abreu ${ }^{\mathrm{a}^{*}}$, Daliane Ferreira Marinho ${ }^{\mathrm{b}^{*}}$, Iana Bruna Parente Cardoso ${ }^{\mathrm{c}^{*}}$ \\ claudia_sarraff@hotmail.coma, dalianemarinho@yahoo.com.br ${ }^{\text {b }}$ ianabruna95@gmail.com \\ Universidade do Estado do Pará
}

Data de recebimento do artigo: 14/11/2018

Data de aceite do artigo: 26/02/2019

\begin{abstract}
RESUMO
Introdução: A utilização de materiais educativos impressos na área da saúde é uma prática comum no Sistema Único de Saúde (SUS). As informações de uma tecnologia educativa auxiliam na tomada de decisão cotidiana do cuidador quanto ao manejo adequado do paciente. Objetivos: Este estudo teve como objetivo elaborar e validar uma tecnologia educativa, do tipo cartilha, para os cuidados de pacientes submetidos a traqueostomia. Materiais e métodos: Tratou-se de uma pesquisa com abordagem quantitativa, sendo realizado em duas fases, sendo a primeira fase de produção da cartilha e a segunda etapa de validação. A coleta de dados foi realizada no hospital municipal de Santarém - Pará, durante o ano de 2018. O instrumento da coleta de dados foi por meio de questionários de avaliação da cartilha. Na análise dos dados, utilizou-se a escala de likert com grau de concordância de no mínimo 80\%. Resultados: A amostra foi composta por 18 voluntários, sendo 13 juízes-especialistas e 5 cuidadores. A análise dos juízes-especialistas alcançou concordância de $97,22 \%$, sendo que no primeiro bloco obteve $100 \%$, no segundo $97,44 \%$ e no terceiro $94,23 \%$. Apesar de todos receberem valor maior que $80 \%$, houve sugestões de modificações na cartilha e que foram acatadas. Já a avaliação do público-alvo obteve concordância de $100 \%$ em todos os blocos e sem sugestões. Conclusão: A cartilha foi considerada válida pelos juízes e cuidadores, devendo ser um recurso complementar para os cuidadores dos pacientes traqueostomizados.
\end{abstract}

Palavras-chaves: Traqueostomia. Manual. Produção. Validação. Orientação.

\section{ABSTRACT}

Introduction: The use of educational materials printed in the health area is a common practice in the Unified Health System (SUS). The information of an educational technology helps in the daily decision making of the caregiver as to the proper management of the patient. Objectives: This study aimed to elaborate and validate a booklet-type educational technology for the care of patients undergoing tracheostomy. Materials and methods: This was a research with a quantitative approach, being carried out in two phases, being the first phase of production of the booklet and the second stage of validation. Data collection was performed at the municipal hospital of Santarém - Pará, during the year 2018. The instrument of data collection was through questionnaires to evaluate the booklet. In the analysis of the data, we used the likert scale with a degree of agreement of at least $80 \%$. Results: The sample consisted of 18 volunteers, 13 judges and 5 caregivers. The analysis of the expert judges reached agreement of $97.22 \%$, and in the first block obtained $100 \%$, in the second $97.44 \%$ and in the third $94.23 \%$. Although all received a value greater than $80 \%$, there were suggestions for modifications in the booklet that were adhered to. On the other hand, the evaluation of the target audience obtained 100\% agreement in all blocks and without suggestions. Conclusion: The booklet was considered valid by judges and caregivers, and should be a complementary resource for caregivers of tracheostomized patients.

Key-words: Tracheostomy. Manual. Production. Validation. Guidance. 


\section{INTRODUÇÃO}

A utilização de materiais educativos impressos na área da saúde é uma prática comum no Sistema Único de Saúde (SUS). Tais orientações de cuidados são disponibilizadas para os usuários através de manuais, folhetos, folders e cartilhas. Esses materiais promovem resultados positivos na melhora do quadro clínico do paciente ${ }^{1,2}$.

As informações de uma tecnologia educativa permitem ao paciente e à sua família uma leitura posterior, que reforçam as orientações verbais, servindo como guia em casos de dúvidas e auxiliando na tomada de decisão cotidiana quanto ao manejo do paciente ${ }^{3}$.

Embora o procedimento da traqueostomia seja realizado com frequência nos hospitais, tem-se observado na prática clínica a escassez de informações para os cuidadores, pois a manipulação não adequada da traqueostomia e do paciente no leito podem ocasionar diversas complicações como obstrução da cânula, estenose subglótica e traqueal, broncoaspiração, deformidades e úlceras de pressão, que resultam em um maior período de hospitalização e até mesmo em óbito no paciente ${ }^{1}$.

Diante disso, é dever da equipe multiprofissional orientar e repassar informações de maneira concisa aos cuidadores quanto às habilidades de cuidados ao paciente traqueostomizado. E, dentro da equipe de saúde é essencial que seja disponibilizado a fisioterapia respiratória e motora ${ }^{4,5}$.

Em hospitais da rede pública do município de Santarém-Pará é possível observar considerável índice de pacientes submetidos a traqueostomia, devido algumas condições clínicas como obstruções das vias aéreas superiores de origem infecciosa, traumática, dificuldade de manipulação de secreções e de suporte ventilatório prolongado ${ }^{6}$. Com base nisso, esse estudo teve como objetivo elaborar e validar uma tecnologia educativa do tipo cartilha, contendo orientações para os cuidadores, com a finalidade de promover uma melhor recuperação e qualidade de vida da pessoa submetida a traqueostomia.

\section{MATERIAIS E MÉTODOS}

Trata-se de um estudo de produção e de validação de uma tecnologia educativa, do tipo cartilha, no qual foi desenvolvida em duas fases distintas, sendo utilizado o método quantitativo durante as duas fases da pesquisa ${ }^{7,8}$.

A fase de produção foi caracterizada pela confecção da cartilha após uma revisão da literatura. Utilizaram-se como critério de inclusão os artigos de evidência científica na literatura dos recentes cinco anos, gratuitamente disponíveis de forma integral e publicados em revistas indexadas nas bases de dados: Literatura Latino-Americana e do Caribe em Ciência da Saúde (LILACS) e Scientific Electronic Library Online (SciELO). Os critérios de exclusão foram textos direcionados para crianças que utilizavam a traqueostomia.

Foi utilizada uma linguagem compreensível com definições, palavras simples, analogias e ilustrações ${ }^{9}$. O trabalho de design e ilustrações das imagens foi realizado por 2 designer gráficos, no qual um foi responsável pela formatação e o outro criou as ilustrações, pois tinha uma experiência na área de desenhos, conforme as edições realizadas, o material era enviado para as pesquisadoras para a aprovação.

A fase de validação ocorreu no hospital municipal de Santarém- PA (HMS), no período de julho a outubro de 2018. Para participar da amostra da pesquisa foram selecionados 13 juízes-especialistas, sendo 9 juízes da área da saúde, 3 fisioterapeutas, 2 médicos, 3 enfermeiros e 1 psicólogo, que trabalhavam no HMS e 4 juízes de outras áreas, que foram 2 pedagogos e 2 designers gráficos.

Os critérios de inclusão para a seleção dos juízes-especialistas da área da saúde foram considerados os seguintes aspectos: ser especialistas e/ou está fazendo especialização na área respiratória e/ou ser intensivista e/ou cirurgia geral e/ou aqueles com pelo menos um ano de experiência na área hospitalar. Já a seleção dos juízes-especialistas de outras áreas profissionais, foi ter no mínimo um ano de experiência na área de atuação.

Também participaram da amostra os cuidadores dos pacientes traqueostomizados, os critérios de inclusão foram: ser familiar, ter idade igual ou superior a 18 anos, ser alfabetizado e participar do processo de visita e/ou acompa- 
nhamento ao paciente internado. Além disso, para serem inclusos os cuidadores na pesquisa, os pacientes deveriam ser adultos e internados nos setores de clínica cirúrgica ou clínica médica do hospital, fazendo uso de traqueostomia e/ou em processo de decanulação.

Os critérios de exclusão foram aqueles que recebessem alta no decorrer da pesquisa ou que vão a óbito ou que mudem de setor hospitalar. Além disso, indivíduos que não aceitem participar da pesquisa.

Para avaliação da cartilha, usou-se o conceito de validade de conteúdo e aparência, ou seja, utilizou-se um questionário que buscou medir a adequação dos itens de avaliação com relação ao conteúdo e a concordância dos tópicos analisados ${ }^{9}$.

Tal questionário é constituído por tópicos que poderiam receber 4 pontuações diferentes de critério de valorização, que foram: pontuação 1 igual a totalmente adequado (TA), pontuação 2 iguais a adequado (A), pontuação 3 iguais a parcialmente adequado (PA) e pontuação 4 iguais a inadequado (I).

Os juízes-especialistas foram os primeiros a responder os questionários referentes à avaliação do conteúdo do material educativo, após assinarem o termo de consentimento livre esclarecido (TCLE). Receberam uma cópia da cartilha para ser avaliada, sendo que foi entregue de volta, em um prazo máximo de 10 dias para as pesquisadoras.

O instrumento de avaliação dos juízes foi dividido em duas partes. No início tinha perguntas quanto aos dados de identificação, formação profissional, área de atuação, titulação e tempo de formação. A segunda parte do questionário foi referente à avaliação da cartilha, sendo avaliados por 4 tópicos, 3 deles com itens que podiam ser pontuados de 1 a 4 e o quarto tópico consistiu em um espaço para comentários e sugestões dos juízes-especialistas. O tópico 1 tratou-se da análise dos objetivos da cartilha. Já o tópico 2 se referiu à análise da estrutura e apresentação do instrumento. $\mathrm{O}$ tópico 3 estava relacionado com o julgamento da relevância da cartilha ${ }^{10}$.

Os cuidadores receberam a $2^{\mathrm{a}}$ versão da cartilha, após a análise dos juízes, e como su- jeitos da pesquisa, eles assinaram o Termo de Consentimento Livre e Esclarecido (TCLE). E após, receberam uma cópia da cartilha para ser avaliada e entregaram de volta, em um prazo máximo de 48 horas.

A primeira parte desse questionário foi constituída de perguntas sócio- demográfica sobre o cuidador e da situação do paciente quanto ao motivo que levou o uso da traqueostomia, período de internação hospitalar e tempo de utilização da traqueostomia e se ele recebeu orientações sobre os cuidados com a traqueostomia. A segunda parte desse questionário para os cuidadores foi sobre a avaliação da cartilha, constituída por 6 tópicos, 5 deles com itens que podiam ser pontuados de 1 a 4 e o quinto tópico consistiu em um espaço para comentários e sugestões. O tópico 1 se tratou da análise dos objetivos da cartilha. Já o tópico 2 se referiu à análise da organização do instrumento. O tópico 3 estava relacionado com o julgamento do estilo da escrita. O tópico 4 analisou a aparência da cartilha. O tópico 5 foi referente a avaliação da motivação do material e o tópico 6 consistiu em um espaço para comentários e sugestões dos cuidadores ${ }^{10}$.

$\mathrm{Na}$ análise de dados dos questionários referentes à cartilha foi utilizada uma representação das opções de respostas dos itens através da escala de Likert, que foram pontuadas de 1 , 2,3 e 4 . Sendo, as respostas 1 e 2, representaram pontuação +1 ; respostas 3 , significaram pontuação 0 e respostas 4 , indicaram pontuação -1. Logo, as respostas de cada avaliador da cartilha variaram de $-1 \mathrm{a}+1$. E, para todos os itens foi considerado válido o grau de concordância igual ou maior a $80 \%$. E para calcular o percentual por coluna de escore (TA, A, PA, I) multiplicou-se o subtotal de um escore por 100 e dividiu-se pela soma de todas as opções de respostas. ${ }^{10,11,12,13}$.

A análise dos dados foi feita através da análise quantitativa, com uso do Excel 2010 para o banco de dados e software Biostat versão 5.0 para interpretação dos resultados.

O projeto foi aprovado pelo comitê de ética em pesquisa (CEP) e obedeceu à resolução 466/12 do Conselho Nacional de Saúde, de acordo com o protocolo: 79506817.3.0000.5168. 


\section{RESULTADOS}

Este estudo foi composto por 18 colaboradores, sendo 13 profissionais da saúde e de outras áreas e 5 cuidadores dos pacientes traqueostomizados.

\section{PERFIL DOS JUIZES-ESPECIALISTAS}

Os resultados apresentados na Tabela 1, refere-se sobre o perfil dos juízes- especialistas da área da saúde. Tabela 1:

Tabela 1 - Perfil dos Juízes- especialistas da área de Saúde.

\begin{tabular}{|c|c|c|c|c|c|c|c|}
\hline \multicolumn{8}{|c|}{ Perfil dos juízes da área de saúde } \\
\hline Juízes & Sexo & $\begin{array}{l}\text { Ida- } \\
\text { de }\end{array}$ & Área de formação & $\begin{array}{l}\text { Tempo de } \\
\text { formação }\end{array}$ & $\begin{array}{l}\text { Tempo de } \\
\text { atuação } \\
\text { no serviço } \\
\text { hospitalar }\end{array}$ & Titulação & $\begin{array}{l}\text { Curso/Trei- } \\
\text { namento em } \\
\text { traqueostomia }\end{array}$ \\
\hline 1 & M & 44 & Medicina & 19 anos & 19 anos & $\begin{array}{l}1 \text { Especializações } \\
\text { (Unidade de Terapia } \\
\text { Intensiva (UTI) }\end{array}$ & Sim \\
\hline 2 & M & 29 & Medicina & 1 anos & 8 anos & $\begin{array}{c}1 \text { Mestrado (Ensino em } \\
\text { Saúde) }\end{array}$ & Não \\
\hline 3 & $\mathrm{~F}$ & 36 & Enfermagem & 7 anos & 5 anos & $\begin{array}{c}1 \text { Especialização } \\
\text { Unidade de Terapia } \\
\text { intensiva) }\end{array}$ & Não \\
\hline 4 & $\mathrm{~F}$ & 28 & Enfermagem & 4 anos & 4 anos & $\begin{array}{c}1 \text { Especialização } \\
\text { Unidade de Terapia } \\
\text { intensiva adulto) }\end{array}$ & Não \\
\hline 5 & $\mathrm{~F}$ & 27 & Enfermagem & 6 anos & 4 anos & $\begin{array}{l}1 \text { Especialização (Ur- } \\
\text { gência e Emergência) }\end{array}$ & Não \\
\hline 6 & $\mathrm{~F}$ & 32 & Fisioterapia & 8 anos & $\begin{array}{l}5 \text { anos e } 8 \\
\text { meses }\end{array}$ & $\begin{array}{c}1 \text { Especialização } \\
\text { (Unidade de Terapia } \\
\text { Intensiva Neonatal e } \\
\text { pediátrica) }\end{array}$ & Sim \\
\hline 7 & $\mathrm{~F}$ & 28 & Fisioterapia & 6 anos & 3 anos & $\begin{array}{l}1 \text { Especialização (Fisio- } \\
\text { terapia em UTI) }\end{array}$ & Não \\
\hline 8 & M & 26 & Fisioterapia & $\begin{array}{l}3 \text { anos e } 6 \\
\text { meses }\end{array}$ & 3 anos & $\begin{array}{c}1 \text { Especialização (Fisio- } \\
\text { terapia em UTI) }\end{array}$ & Não \\
\hline 9 & $\mathrm{~F}$ & 28 & Psicologia & 6 anos & $\begin{array}{l}1 \text { ano e } 4 \\
\text { meses }\end{array}$ & $\begin{array}{c}1 \text { Especialização (Neu- } \\
\text { ropsicologia) }\end{array}$ & Não \\
\hline
\end{tabular}

UTI: Unidade de Terapia intensiva.

Fonte: Dados da pesquisa (2018).

Destes 9 juízes da área da saúde, 6 (66,67\%) foram mulheres e apenas $3(33,33 \%)$ consistiram de homens. Quanto ao tempo de formação, o menor foi de 1 anos e o maior de 19 anos, com uma média de 6,7 anos. Já em relação ao tempo de atuação no serviço hospitalar, percebemos que o menor tempo foi de um 1 ano e 4 meses e o maior tempo consistiu de 19 anos, com uma média de 5,9 anos. Já em relação à titulação, 8 dos profissionais tinham especialização representando $88,89 \%$ dos juízes-especialistas da área da saúde e apenas 1 juiz continha mestrado representando $11,11 \%$.

Em relação à participação em curso ou treinamento em traqueostomia, apenas 2 dos juízes tiveram respostas afirmativas, referente a $22,22 \%$ dos juízes-especialistas.

Os resultados apresentados abaixo na Tabela 2 se refere ao perfil dos juízes-especialistas de outras áreas. Tabela 2: 
Tabela 2 - Perfil dos juízes-especialistas de outras áreas.

\begin{tabular}{cccccc}
\hline \multicolumn{7}{c}{ Juízes } & Sexo & Idade & Área de formação & $\begin{array}{c}\text { Tempo de } \\
\text { formação }\end{array}$ & Titulação \\
\hline 10 & F & 36 & Pedagogia & 10 anos & 1 Especialização (Gestão escolar) \\
11 & F & 27 & Pedagogia & 3 anos & Mestrado \\
12 & M & 21 & Designer Gráfico & 1 Ano & Graduação \\
13 & M & 21 & Designer Gráfico & 2 anos & Graduação
\end{tabular}

Fonte: Dados da pesquisa (2018).

Todos os juízes-especialistas de outras áreas eram adultos, entre eles, dois homens e duas mulheres com idade entre 21 a 36 anos, sendo uma idade média de 26 anos. Já em relação ao tempo de formação o mínimo foi de 1 anos e o máximo de 10 anos, com tempo médio de 4 anos. Quanto à titulação, 1 possuía especialização, sendo da área de gestão escolar, 1 continha mestrado, os demais tinham somente a graduação.

\section{Perfil do público alvo}

Os resultados apresentados na Tabela 3 se refere ao perfil sociodemográfico dos cuidadores. Tabela 3:

Tabela 3 - Perfil dos cuidadores avaliadores da cartilha.

\begin{tabular}{|c|c|c|c|c|c|c|c|c|}
\hline \multicolumn{9}{|c|}{ Perfil dos cuidadores } \\
\hline Cuidador & Sexo & Idade & Profissão & $\begin{array}{c}\text { Grau de } \\
\text { Escolaridade }\end{array}$ & $\begin{array}{c}\text { Estado } \\
\text { Civil }\end{array}$ & Procedência & $\begin{array}{l}\text { Motivo e Tempo de } \\
\text { Internação }\end{array}$ & $\begin{array}{c}\text { Motivo e tempo } \\
\text { de utilização da } \\
\text { traqueostomia }\end{array}$ \\
\hline 1 & M & 44 & $\begin{array}{c}\text { Carpinteiro } \\
\text { Naval }\end{array}$ & EMC & Casado & Oriximiná & $\begin{array}{l}\text { Traumatismo cra- } \\
\text { niano grave; } 30 \text { dias }\end{array}$ & $\begin{array}{l}\text { Facilitar a respi- } \\
\text { ração; } 20 \text { dias; }\end{array}$ \\
\hline 2 & $\mathrm{~F}$ & 29 & $\begin{array}{l}\text { Repre- } \\
\text { sentante } \\
\text { comercial }\end{array}$ & ESC & Solteira & Santarém & Cirúrgica; 43 dias & $\begin{array}{c}\text { Tempo prolo- } \\
\text { gando na VM; } \\
29 \text { dias; }\end{array}$ \\
\hline 3 & $\mathrm{~F}$ & 55 & Doméstica & EFC & Casada & Santarém & $\begin{array}{c}\text { AVE hemorrágico } \\
\text { e pneumonia; } \\
31 \text { dias }\end{array}$ & $\begin{array}{l}\text { Facilitar a respi- } \\
\text { ração; } 25 \text { dias }\end{array}$ \\
\hline 4 & M & 27 & Garçom & EMC & Solteiro & Santarém & $\begin{array}{l}\text { AVE e Pneumonia } \\
\text { grave; } 20 \text { dias }\end{array}$ & $\begin{array}{c}\text { Tempo prolon- } \\
\text { gado na VM; } \\
120 \text { dias }\end{array}$ \\
\hline 5 & $\mathrm{~F}$ & 50 & $\begin{array}{l}\text { Vendedora } \\
\text { autônoma }\end{array}$ & EMI & Solteira & Santarém & AVE; 30 dias & $\begin{array}{l}\text { Facilitar a respi- } \\
\text { ração; } 10 \text { dias }\end{array}$ \\
\hline
\end{tabular}

EFC: Ensino Fundamental Completo; EM: Ensino Médio Completo; Ensino médio Incompleto, ESC: Ensino Superior Completo; AVE: Acidente Vascular Encefálico; VM: Ventilação Mecânica.

Fonte: Dados da pesquisa (2018).

Destes 5 cuidadores, que realizaram a avaliação da cartilha, 2 (40\%) foram homens e 3 (60\%) constituíram de mulheres. Já em relação à idade houve uma média de $41 \%$ de anos. Observou-se que $4(80 \%)$ dos cuidadores tiveram a procedência de Santarém, local onde os dados foram coletados e 1 (20\%) de Oriximiná. Já quanto ao tempo de internação houve uma variação de 30 até 43 dias, sendo a média de $30,8 \%$ dias. Em relação ao tempo de uso da traqueostomia teve uma variação de 10 até 120 dias, sendo a média de $40,8 \%$ dias. 
Quanto ao motivo de internação, 3 (60\%) foi por Acidente Vascular Encefálico, 1 (20\%) aconteceu devido um Traumatismo Craniano e 1 (20\%) foi em consequência de uma cirurgia. Em relação ao motivo da utilização da traqueostomia, 3 (60\%) foi para facilitar a respiração e $2(40 \%)$ devido ao tempo prolongado na ventilação mecânica.

Outro ponto investigado com os cuidadores desta pesquisa foi quanto ao recebimento ou não de orientações sobre a traqueostomia. Observou-se que $4(80 \%)$ dos cuidadores receberam orientações e apenas 1 (20\%) não tinha recebido. O ideal seria, que todos tivessem recebido orientações. Segundo o estudo de Vieira ${ }^{14}$, a equipe de saúde do sistema hospitalar, nem sempre ofereceram o apoio esperado pelos cuidadores, principalmente no que se refere ao fornecimento de explicações sobre os diferentes aspectos da doença e do seu tratamento. Fazendo com que estes cuidadores no ambiente domiciliar, sintam-se inseguros.

\section{VERSÃO DA CARTILHA}

O conteúdo do material educativo gerou uma impressão colorida, com os tópicos destacados em negrito. Sendo obedecida uma sequência lógica, desde a admissão do paciente no hospital até uma eventual alta.

No início da cartilha, tinha uma apresentação para esclarecer o seu objetivo, abordando a temática sobre os cuidados com a traqueostomia. Em seguida, através de perguntas e respostas, conceituou-se traqueostomia, mostrando para o leitor as orientações sobre limpeza da cânula, higiene pessoal, cuidados com a alimentação, posicionamento do paciente e outras orientações. Também foram esclarecidos para o leitor sobre a importância da fisioterapia para o paciente e ensinados alguns exercícios respiratórios e motores.

A confecção da cartilha passou por duas versões, sendo entregue a segunda versão revisada para os cuidadores, após sugestões e comentários dos juízes-especialistas sobre o texto e ilustrações (tabela 4). As mesmas foram acatadas até a versão final da cartilha educativa.

Constatou-se que 3 juízes (23,08 \%) optaram por assinalar e sugerir ajustes, sendo que em meio a essas sugestões ou de forma isolada, também foram feitos $4(30,77 \%)$ comentários referentes a cartilha e $6(46,15 \%)$ optaram por assinalar e não comentar. Tabela 4:

Tabela 4: Sugestões e comentário dos juízes-especialistas sobre a cartilha.

\section{Sugestões e comentário dos juízes-especialistas}

Tópico 8 Quanto aos tipos de cânula. Existem cânulas fonadas.

Tópico 13 Quanto à fala: Especificar os tipos de traqueostomia, por exemplo: a traqueostomia plástica só permite a fala se o cuff estiver seco e e somente assim pode ser ocluída.

Tópico 14 Figura 15 da cartilha: Imagem não condiz com a legenda.

Análise geral Sugiro rever concordância e ortografia. Na minha observação faltou algum ajuste, talvez até de digitação.

O instrumento educativo está bem elaborado, as informações do conteúdo para os cuidadores de pacientes submetidos à traqueostomia estão claras e objetivas. O material contém um processo técnico e científico, podendo circular no meio científico da área e também contri-

Análise geral buir para o cuidador. $\mathrm{O}$ assunto da traqueostomia tem uma metodologia adequada e específica sobre o conteúdo abordado no instrumento educativo, possui uma dinâmica didática em fontes de informações de caráter explicativo das orientações da traqueostomia para os cuidadores de pacientes com essa demanda. Portanto, o instrumento mostra a transmissão do conhecimento em diferentes campos de atuação como na saúde e educação.

Análise geral Alguns erros ortográficos.

Análise geral Muito bem elaborada.

Análise geral

Excelente instrumento. Confeccionado com muito zelo e capricho. Excelente material complementar para o ensino de cuidadores com impacto direto na assistência dos pacientes. 
"Eu, como pessoa totalmente leiga no assunto achei a cartilha muito interessante e muito bem organizada. As informações contidas na cartilha são bastante claras e acessíveis a todos os níveis de conhecimento, o único aspecto que me causou incômodo foi o tamanho da letra Análise geral no texto, mas ao analisar mais profundamente percebi que a fonte utilizada é comparável as fontes utilizadas em bula de remédio, mesmo assim ainda considero pequena. Minha análise geral é que é bastante explicativa e que não apresenta dificuldade de interpretação em nenhum dos textos apresentados. Como já citei: eu como leiga no assunto, aprendi muito com a cartilha".

Fonte: Dados da pesquisa (2018).

Os principais comentários dos cuidadores estão listados na tabela 5. Constatou-se que apenas 2 (40\%) cuidadores optaram por assinalar e comentar e 3 (60, $\%)$ escolheram assinalar e não comentar. Tabela 5:

Tabela 5: Comentários dos cuidadores sobre a cartilha

Comentários dos cuidadores

Comentário 1

Comentário 2

Fonte: Dados da pesquisa (2018).

A versão final da cartilha conteve 44 ilustrações, 31 páginas, disposto em frente e verso, contendo: capa, sumário conteúdo, curiosidades, vocabulário, anotações e ficha técnica.

\section{AVALIAÇÃODOSJUIZESESPECIALISTAS}

As respostas obtidas dos questionários dos juízes-especialistas foram analisadas de forma quantitativa e expostas na Tabela 6, de acordo com a ordem do questionário e a sequência dos três blocos (1. Objetivos; 2. Estrutura e apresentação; e 3. Relevância) dos itens avaliados. Tabela 6:

Tabela 6 - Ordenamento das respostas dos juízes especialistas segundo objetivos, estrutura e apresentação, relevância e índice percentuais de concordância de cada item.

\begin{tabular}{|c|c|c|c|c|c|}
\hline ITENS & & & (13) & & \\
\hline BLOCO 1 & TA & A & PA & I & $\begin{array}{l}\text { Índice de concordância } \\
\text { por bloco }\end{array}$ \\
\hline $\begin{array}{l}\text { 1.1. As informações são importantes para } \\
\text { o cuidador de pacientes submetidos a } \\
\text { traqueostomia? }\end{array}$ & 10 & 3 & 0 & 0 & 0,100 \\
\hline $\begin{array}{l}\text { 1.2 Convida e/ou instiga a mudanças de } \\
\text { comportamento e atitude do cuidador de } \\
\text { pacientes submetidos a traqueostomia? }\end{array}$ & 7 & 6 & 0 & 0 & 0,100 \\
\hline $\begin{array}{l}\text { 1.3 Pode circular no meio científico da } \\
\text { área? }\end{array}$ & 9 & 4 & 0 & 0 & 0,100 \\
\hline $\begin{array}{l}\text { 1.4 A TE atende aos objetivos da atenção à } \\
\text { saúde para o cuidador de pacientes subme- } \\
\text { tidos a traqueostomia? }\end{array}$ & 9 & 4 & 0 & 0 & 0,100 \\
\hline
\end{tabular}




\begin{tabular}{|c|c|c|c|c|c|}
\hline Subtotal & 35 & 17 & 0 & 0 & \\
\hline Percentual por bloco & & & & & $100 \%$ \\
\hline \multicolumn{6}{|l|}{ BLOCO 2} \\
\hline $\begin{array}{l}2.12 .1 \text { A cartilha é apropriada para os } \\
\text { cuidadores de pacientes submetidos a } \\
\text { traqueostomia? }\end{array}$ & 8 & 4 & 1 & 0 & 0,92 \\
\hline $\begin{array}{l}2.2 \text { As mensagens estão apresentadas de } \\
\text { maneira clara e objetivas? }\end{array}$ & 8 & 5 & 0 & 0 & 0,100 \\
\hline $\begin{array}{l}\text { 2.3 As informações apresentadas estão } \\
\text { cientificamente corretas? }\end{array}$ & 8 & 5 & 0 & 0 & 0,100 \\
\hline $\begin{array}{l}2.4 \text { O material está apropriado a pacientes } \\
\text { de qualquer nível sociocultural? }\end{array}$ & 7 & 6 & 0 & 0 & 0,100 \\
\hline $\begin{array}{l}2.5 \text { Há uma sequência lógica de conteúdo } \\
\text { proposto? }\end{array}$ & 8 & 5 & 0 & 0 & 0,100 \\
\hline $\begin{array}{l}\text { 2.6 As informações estão bem estrutura- } \\
\text { das em concordância e ortografia, numa } \\
\text { linguagem acessível aos pacientes? }\end{array}$ & 5 & 6 & 2 & 0 & 0,84 \\
\hline $\begin{array}{l}2.7 \text { O estilo da redação corresponde ao } \\
\text { nível }\end{array}$ & 9 & 4 & 0 & 0 & 0,100 \\
\hline $\begin{array}{l}2.8 \text { As informações da capa, sumário e } \\
\text { apresentação são coerentes? }\end{array}$ & 9 & 4 & 0 & 0 & 0,100 \\
\hline $\begin{array}{l}2.9 \text { O tamanho do título e dos tópicos estão } \\
\text { adequados? }\end{array}$ & 6 & 7 & 0 & 0 & 0,100 \\
\hline Subtotal & 68 & 46 & 3 & 0 & \\
\hline Percentual por bloco & & & & & $97,44 \%$ \\
\hline \multicolumn{6}{|l|}{ BLOCO 3} \\
\hline $\begin{array}{l}\text { 3.1 Os temas retratam aspectos-chave que } \\
\text { devem ser reforçados? }\end{array}$ & 8 & 4 & 1 & 0 & 0,92 \\
\hline $\begin{array}{l}3.2 \mathrm{O} \text { material permite a transferência e } \\
\text { generalização do aprendizado a diferentes } \\
\text { contextos (cuidadores de pacientes subme- } \\
\text { tido a traqueostomia)? }\end{array}$ & 8 & 4 & 1 & 0 & 0,92 \\
\hline $\begin{array}{l}\text { 3.3 A cartilha propõe a construção de } \\
\text { conhecimento ou mudanças de comporta- } \\
\text { mentos? }\end{array}$ & 7 & 6 & 0 & 0 & 0,100 \\
\hline $\begin{array}{l}3.4 \mathrm{O} \text { material aborda os assuntos necessá- } \\
\text { rios para o saber dos cuidadores de pacien- } \\
\text { tes submetidos a traqueostomia? }\end{array}$ & 8 & 4 & 1 & 0 & 0,92 \\
\hline Subtotal & 31 & 18 & 3 & 0 & \\
\hline Percentual por bloco & & & & & $94,23 \%$ \\
\hline Total & 134 & 81 & 6 & 0 & \\
\hline PERCENTUAL TOTAL & & & & & $97,22 \%$ \\
\hline
\end{tabular}

TA: Totalmente Adequado. A: Adequado. PA: Parcialmente Adequado. I: Inadequado.

Fonte: Dados da pesquisa (2018). 


\section{AVALIAÇÃO DOS CUIDADORES}

As respostas obtidas dos questionários dos cuidadores foram analisadas de forma quantitativa, expostas na Tabela 7, de acordo com a ordem do questionário e a sequência dos cinco blocos (1. Objetivos; 2. Organização; 3. Estilo da escrita; 4. Aparência; e 5. Motivação) dos itens avaliados. Tabela 7:

Tabela 7 - Ordenamento das respostas dos cuidadores segundo objetivos, organização, estilo da escrita, aparência, motivação e índice percentuais de concordância de cada item.

\section{ITENS}

\section{BLOCO 1}

1.1 A cartilha atendeu aos seus objetivos de orientação?

1.2 Ajuda a você a promover uma melhor qualidade de vida, nesse momento ao paciente? 1.3 A cartilha está adequada para ser usado por você cuidador nesse momento de utilização da traqueostomia pelo paciente?

Subtotal

Percentual por bloco

BLOCO 2

2.1 A capa é atraente e indica o conteúdo da cartilha?

2.2 O tamanho do título e do conteúdo nos tópicos está adequado?

2.3 Os tópicos estão em sequência que facilite o entendimento?

2.4 Há coerência entre as informações da capa, contracapa, sumário, agradecimentos e/ou apresentação?

$2.5 \mathrm{O}$ material (papel/impressão) está apropriado?

$2.6 \mathrm{O}$ número de páginas está adequado?

2.7 Os temas retratam aspectos importantes?

Subtotal

Percentual por bloco

BLOCO 3

3.1 1 A escrita está em estilo que facilite o entendimento?

$3.2 \mathrm{O}$ texto é interessante?

$3.3 \mathrm{O}$ vocabulário é de fácil compreensão?

3.4 Há associação do tema de cada sessão ao texto correspondente?

$3.5 \mathrm{O}$ texto está claro para você?

$3.6 \mathrm{O}$ estilo da redação corresponde ao nível do seu conhecimento?
SCORES (13)

$\begin{array}{ccccc}\text { TA } & \text { A } & \text { PA } & \text { I } & \text { por bloco } \\ 4 & 1 & 0 & 0 & 0,100 \\ 4 & 1 & 0 & 0 & 0,100 \\ 5 & 0 & 0 & 0 & 0,100 \\ 13 & 2 & 0 & 0 & 100 \%\end{array}$

4

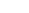

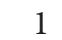

0

0

0,100

2

4

23

3

3
3
1
12

$$
0
$$

0

0,100

$0 \quad 0$

0,100

$0 \quad 0$

0,100

0

$100 \%$

$\begin{array}{lllll}3 & 2 & 0 & 0 & 0,100 \\ 4 & 1 & 0 & 0 & 0,100 \\ 3 & 2 & 0 & 0 & 0,100 \\ 5 & 0 & 0 & 0 & 0,100 \\ 4 & 1 & 0 & 0 & 0,100 \\ 2 & 3 & 0 & 0 & 0,100\end{array}$




\section{Subtotal}

Percentual por bloco

\section{BLOCO 4}

4.1 As páginas ou seções parecem organizadas?

4.2 As ilustrações/fotografias são de fácil entendimento?

4.3 As ilustrações/fotografias servem para complementar os textos?

4.4 As ilustrações/fotografias estão expressivas e suficientes?

Subtotal

Percentual por bloco

BLOCO 5

5.1 A cartilha é adequada para você?

5.2 Os conteúdos da cartilha se apresentam de forma lógica?

5.3 A cartilha aborda os assuntos necessários para o dia a dia do cuidador de pacientes submetidos a traqueostomia?

5.4. Convida/instiga a mudanças de comportamento e atitude do cuidador durante a internação do paciente?

5.5 A cartilha propõe conhecimentos para você?

Subtotal

Percentual por bloco

TOTAL

PERCENTUAL TOTAL

$$
0
$$$$
0
$$$$
4
$$$$
3
$$

2

0

0

0,100

2

0

0

0,100

$0 \quad 0$

0,100

7

$0 \quad 0$

0

4

1

0

0

0,100

4

1

0

0

0,100

5

0

0

0

0,100

1

$0 \quad 0$

0,100

300

$92 \quad 33 \quad 0 \quad 0$
$100 \%$

$100 \%$

TA: Totalmente Adequado. A: Adequado. PA: Parcialmente Adequado. I: Inadequado.

Fonte: Dados da pesquisa (2018).

\section{DISCUSSÃO}

Os profissionais de saúde, produtores de material impresso devem ter em mente, que um material educativo deve ser adequadamente planejado e validado para atender a necessidade da pessoa traqueostomizada ${ }^{15}$.

As respostas dos questionários foram consideradas válidas, pois obtiveram concordância maior do que $80 \%$, valor comumente utilizado em outras pesquisas como a de Nascimento ${ }^{10}$, que também se trata de um estudo de validação de instrumento educativo.
Conforme a Tabela 6 houve propensão a respostas concordantes entre os juízes para valoração TA: $134(60,63 \%)$ e A: $81(36,65 \%)$, sendo que as duas foram somadas (soma das respostas TA e A) $97,28 \%$, pois segundo a escala de Likert, utilizada nesta pesquisa, respostas TA e A devem receber valor +1 , pontuação máxima significando concordância entre os juízes. E dos 17 itens, apenas seis obtiveram alguma resposta PA (2,71\%) e nenhuma resposta I (0\%). A cartilha recebeu uma aprovação total de $97,22 \%$, pode-se deduzir que não houve discordância.

$\mathrm{Na}$ literatura há poucos estudos que enfatizam sobre a confecção e validação de materiais 
educativos para pacientes acometidos com alguma patologia respiratória, no entanto, valores semelhantes de concordância ao encontrado na presente pesquisa foram encontrados no estudo de Cardoso ${ }^{16}$, responsável pela criação e validação de uma cartilha destinada ao autocuidado de pacientes submetidos ao dreno torácico. Neste estudo a primeira versão do instrumento foi avaliada por 13 juízes-especialistas, havendo uma propensão a respostas para valoração TA: 221 $(89,47 \%)$ e A: $24(9,71 \%)$, atingindo uma concordância geral de 99, 98\%.

BLOCO 1: Objetivo- tópico referente ao propósito que se deseja alcançar com a cartilha educativa. Ao analisar a valorização atribuída pelos juízes para este bloco, verificou-se: 35 (67,30\%) para TA, $17(32,69 \%)$ para A, $0(0 \%)$ para PA e 0 (0\%) para I. De acordo com as opções de respostas acima das $52(100 \%)$, todas foram para TA e A, conferindo a aceitação dos itens desse bloco, tornando a cartilha adequada quanto aos objetivos.

Resultado semelhante ao encontrado na pesquisa de Sousa (2011) $)^{17}$, que se trata de um estudo de construção e validação de uma tecnologia educativa para pacientes submetidos à cirurgia ortognática em que nenhum item foi julgado em PA e I quanto aos objetivos da cartilha, pois todos dos juízes os classificou como TA ou A, o que conferiu uma concordância de $100 \%$ para os objetivos propostos.

BLOCO 2: Estrutura e Apresentação- refere-se a forma de apresentação das informações para o público, aspectos como organização geral, formatação, estrutura, coerência e ilustrações. Neste aspecto, as respostas dos juízes foram: $68(58,11 \%)$ para TA, $46(39,31 \%)$ para A, $3(2,56 \%)$ para PA e $0(0 \%)$ para I. Portanto, das $117(100 \%)$ opções de respostas dos itens desse bloco, 114 (97,42\%) foram TA e A, confirmando que a cartilha é válida quanto à estrutura e apresentação.

Corroborando com este achado quanto a estrutura e a apresentação da cartilha, a pesquisa de Wild ${ }^{18}$, que se trata de validação de uma cartilha para prevenção da dengue, em que os itens TA e A receberam concordância de $94 \%$, apesar de esse valor ser considerado válido, o autor relata que esse bloco recebeu maior discordância entre os juízes, constituindo a etapa de maior complexidade para a elaboração do material, pois envolveu as- pectos como: layout, grafismo, designer e linguagem adequada para o público-alvo.

Diante disso, todo material educativo deve ter um adequado layout, cor apropriada para o contexto, adequação da linguagem científica à linguagem do público-alvo, tipo de papel, criação de ilustrações e títulos. Todos esses requisitos são essenciais no processo de validação para que a cartilha não chegue inapropriado ao público-alvo ${ }^{10}$.

De acordo com Teles e colaboradores ${ }^{19}$, em relação à apresentação, as informações devem ser repassadas não apenas verbalmente, mas através de tecnologias educativas, que contenham textos informativos e imagens que ilustrem como o cuidado deve ser realizado e também para facilitar a compreensão do texto. Estes devem conter linguagem simples, de maneira que os indivíduos compreendam o que está escrito.

Foi sugerida por 2 juízes, uma correção ortográfica da primeira versão da cartilha, sendo também evidenciado no BLOCO 2 com índice de concordância de $0,84 \%$ do item referente a ortografia. Apesar de a cartilha ser considerada válida, tal sugestão foi atendida, o que permitiu a correção por um professor da língua portuguesa. Segundo Porto e Gurgel ${ }^{20}$, o pesquisador deve, sempre que necessário, pedir a revisão e a correção ortográfica, da pontuação e da gramática de todo o texto. Para que o leitor possa fazer uma leitura coerente do material educativo ${ }^{21}$.

O procedimento de confecção do conteúdo passou por um processo de revisão, após a análise dos juízes-especialistas. As preferências dos juízes, bem como a cultura e o julgamento profissional foram considerados no processo de educação em saúde. Pois é essencial que o material educativo atenda às expectativas dos profissionais, os quais podem colaborar na construção do instrumento educativo que será disponibilizado ao público-alvo ${ }^{22}$.

A cartilha possui o título de "Orientações para os cuidadores de pacientes traqueostomizados", sendo mantido esse tema até a versão final da cartilha. Segundo Cordeiro e colaboradores ${ }^{23}$ é importante que seja escolhido um tema para que o conteúdo seja atrativo e que haja uma boa leitura e compreensão.

BLOCO 3: Relevância- trata-se das características que indicam o grau de significação/importância da cartilha. Neste bloco, as respostas fo- 
ram: $31(59,61 \%)$ para TA, $18(34,61 \%)$ para A, 3 $(5,76 \%)$ para PA e $0(0 \%)$ para I. Portanto, das 52 (100\%) opções de respostas dos itens desse bloco, 49 (94,22\%) foram TA e A, confirmando que a cartilha é válida quanto à relevância.

Tal resultado é semelhante ao encontrado na pesquisa de Bezerra ${ }^{24}$, que se trata da construção e validação de uma cartilha educativa sobre eventos adversos pós-vacinação, em que neste bloco de relevância das 28 opções de respostas, 25 (89,28\%) foram para TA e A, $2(7,14 \%)$ consistiu para PA e $1(3,57 \%)$ para I, confirmando que a cartilha foi considerada válida quanto à relevância.

Segundo Oliveira ${ }^{13}$ os materiais educativos escritos no contexto da educação em saúde é de extrema relevância e contribui no processo de prevenção de complicações, além de possibilitar o desenvolvimento de habilidades e autonomia do cuidador.

Os materiais educativos assumem um papel importante no processo da educação em saúde, pois além de facilitarem a divulgação de conteúdos de aprendizagem, funcionam como um recurso que pode ser disponível para o paciente e sua família. E que eles possam consultá-lo quando tiverem dúvidas no processo do cuidado ${ }^{5}$.

No decorrer da pesquisa para a elaboração do conteúdo da cartilha, percebeu-se a carência de tecnologias educativas com informações para os cuidadores de pacientes traqueostomizados, quando divulgadas, possuíam poucas orientações. Os autores Assis e colaboradores ${ }^{25}$ ressaltam que o material escrito é importante no processo de educação em saúde, uma vez que permite que o público alvo aprenda e aprofunde seus conhecimentos em caso de dúvidas, para que possam auxiliá-lo na tomada de decisão.

A validação aparente com os cuidadores teve como objetivo identificar como o público alvo compreendeu os itens da cartilha ${ }^{10}$. Os dados obtidos foram expostos na tabela 7 , havendo propensão a respostas concordantes para valoração TA:92 (73.6\%) e A: 33 (26,4\%), sem respostas PA (0\%) e nem I (0\%). Ou seja, a cartilha recebeu aprovação de $100 \%$ por parte destes avaliadores nos cinco blocos analisados, alcançando o grau de significância de validação.

Dado similar à pesquisa de Cardoso ${ }^{16}$, em que após a análise do público-alvo, todos os itens avaliados demonstraram a superioridade para a valorização TA: $279(85,85 \%)$ e A: $46(14,15 \%)$, nenhuma resposta para PA (0) e I (0), tendo os percentuais de concordância entre os cinco blocos (objetivos, organização, estilo da escrita, aparência e motivação) de $100 \%$, sendo considerada válida.

A avaliação da $2^{\text {a }}$ versão da cartilha pelos cuidadores demonstrou que seu conteúdo foi escrito de acordo com a realidade de vida diária deles, considerando-se a avaliação positiva que fizeram do material, principalmente em relação ao vocabulário e ilustrações de fácil compreensão. Segundo o estudo de Oliveira e colaboradores ${ }^{26}$, os voluntários de sua pesquisa demonstraram uma avaliação positiva da cartilha com relação às ilustrações como forma complementar aos textos, motivação para leitura e respeito aos aspectos culturais, além da clareza da escrita.

Houve um número reduzido de cuidadores no período da coleta de dados, devemos entender que vários fatores influenciaram a carência de pacientes traqueostomizados como as limitações metodológicas. Pereira ${ }^{27}$ relata que muitos fatores explicam a variação de resultados alcançados por diferentes investigações, entre os quais se encontram os tipos de delineamento, os cenários em que as pesquisas se realizam, os critérios de classificação para incluir ou excluir pacientes da pesquisa e o tempo.

\section{CONCLUSÃO}

A tecnologia utilizada mostrou-se válida, esclarecendo dúvidas, fornecendo conhecimentos sobre os cuidados com o paciente traqueostomizado, segundo a avaliação de juízes especialistas e público-alvo. Quanto à validação, houve comprovação do instrumento como estatisticamente válido para ser usado com o público-alvo, pois a concordância entre os juízes-especialistas ultrapassou o grau de concordância proposto de $80 \%$. Apesar do número inferior de cuidadores que participaram da pesquisa, o que salienta a necessidade de complementar mais número de participantes, notou-se estatisticamente um grau de concordância de $100 \%$.

A divulgação de tecnologias para educação em saúde tem-se mostrado de grande relevância. Diante disso, pretende-se posteriormente subme- 
ter à cartilha como um recurso complementar para os cuidadores, disponibilizados em hospitais, para que ajude nos cuidados com os pacientes traqueostomizados.

\section{AGRADECIMENTOS}

A elaboração deste trabalho não teria sido possível sem a colaboração, estímulo e empenho de diversas pessoas. Gostaria, por este fato, de expressar toda a minha gratidão e apreço a todos aqueles que, direta ou diretamente, contribuíram para que esta pesquisa se tornasse uma realidade. A todos quero manifestar os meus sinceros agradecimentos.

\section{Referências}

1. Alves AO. Criação de uma cartilha de material informativo: cuidados aos pacientes traqueostomizado. [Dissertação Mestrado profissionalizante em Terapia Intensiva]. São Paulo. Pós-Graduação Profissionalizante da Sociedade Brasileira de Terapia Intensiva; 2013.

2. Reberte LM. Celebrando a vida: Construção de uma cartilha para promoção da saúde da gestante. [Dissertação Mestrado]. São Paulo: Escola de Enfermagem. Universidade de São Paulo. 2008. Disponível em: <http://bvsms.saude.gov. br/bvs/publicacoes/premio2009/luciana_magnoni.pdf>.

3. Freitas FV, Rezende Filho LA. Modelos de comunicação e uso de impressos na educação em saúde: uma pesquisa bibliográfica. Rev. Interface Comum. Saúde Educ. 2011; 15(36):243-55.

4. Freitas AAS; Cabral IE. O cuidado à pessoa traqueostomizada: análise de um folheto educativo. Rev. Enferm. 2008;12(1):84-9, 2008 .

5. Sarmento GJV. Fisioterapia respiratória de A a Z. Barueri-São Paulo: Manole; 2016.

6. Pereira EW, Pereira MNS, Siqueira TEA, Oliveira PA. Assistência fisioterapêuticas em um paciente em um paciente crítico internado na UTI de um hospital municipal no interior da Amazônia: Um estudo de caso. Rev. Digital 2015;20(208)

7. Castro ANP, Júnior EML. Desenvolvimento e validação de cartilha para pacientes vítimas de queimaduras. Rev. Bras. Queimaduras 2014;13(2):103-13.

8. Fonseca JJS. Metodologia da pesquisa científica. Fortaleza: UEC. Apostila; 2002

9. Polit DF, Beck CT, Hungler BP. Fundamentos de pesquisa em enfermagem: métodos, avaliação e utilização. 5. ed. Porto Alegre: Artmed; 2004.
10. Nascimento MHM. Tecnologia para mediar o cuidar-educando no acolhimento de "familiares cangurus" em unidade neonatal: Estudo de Validação. [Dissertação Mestrado em Enfermagem]. Universidade do Estado do Pará, Belém; 2012.

11. Fernandes MVL. Indicadores de avaliação de práticas de controle e prevenção de infecção do trato urinário associado a cateter: construção e validação [dissertação]. São Paulo: Escola de Enfermagem. Universidade de São Paulo; 2005 .

12. Silva CPR. Indicadores para avaliação de programas de controle de infecção hospitalar: construção e validação [Dissertação Mestrado]. São Paulo: Escola de Enfermagem. Universidade de São Paulo; 2005.

13. Oliveira MS. Autocuidado da mulher na reabilitação da mastectomia: estudo de validação de aparência e de conteúdo de uma tecnologia educativa. [Dissertação Mestrado]. Fortaleza: Universidade Federal de Fortaleza; 2006.

14. Vieira, MCU. Sentimentos, saberes e fazeres do cuidador principal do idoso com câncer. [Dissertação Mestrado]. Pós-Graduação em Enfermagem, Universidade Estadual de Maringá, Maringá; 2006.

15. Vasconcellos SPR, Roberto P, Silva APP, Rozemberg B. Próteses de comunicação e alinhamento comportamental: uma revisão da literatura sobre impressos hospitalares. Rev. Saúde Pública 2003;37(4):531-42. doi: 10.1590/ S0034-89102003000400021.

16. Cardoso, IBP. Tecnologia educativa para o autocuidado de pacientes submetidos ao dreno torácico. Trabalho de conclusão de curso (Graduação em Fisioterapia) - Universidade do Estado do Pará, Santarém; 2017.

17. Sousa, CS. Educação pós-operatória: construção e validação de uma tecnologia educativa para pacientes submetidos à cirurgia ortognática. [Dissertação de mestrado em enfermagem]. São Paulo: Escola de Enfermagem, Universidade de São Paulo; 2011.

18. Wild, CF. Validação de uma tecnologia educacional com vistas à prevenção da dengue. [Dissertação Mestrado]. Pós-Graduação em Enfermagem, Universidade Federal de Santa Maria, Santa Maria; 2017.

19. Teles LMR, Oliveira AS, Campos FC, Lima TM, Costa CC, Gomes LFS, Oriá MOB, Damasceno AKC. Construção e validação de manual educativo para acompanhantes durante o trabalho de parto e parto. Rev. Esc. Enferm. USP, São Paulo 2014; 48(6): 977-84.

20. Porto F, Gurgel JL. Sugestão de roteiro para avaliação de um artigo científico. Rev. Bras. Ciênc. Esporte 2018;40(2): 111-116.

21. Paula CLM, Santos EVL, Maia PCGGS, Gouveia Filho PS, Sousa MNA. Qualidade de vida de idosos participantes de um grupo de convivência no município de São Mamede - PB. Rev. Bra. Edu. Saúde 2016; 6(2): 01-07. 
22. Pearson A, Wiechula R, Court A, Lockwood C. The JBI Model of evidence-based healthcare. Rev. Int JEB Healthcare 2005; 3(8):207-15. doi: 10.1111/j.14796988.2005.00026.x.

23. Cordeiro LI, Lopes TO, Lira LEA, Feitoza SMS, Bessa MEP, Feitoza AR, Souza AR. Validation of educational booklet for HIV/Aids prevention in older adults. Rev. Bras. Enferm. 2017;70(4):808-815. doi: dx.doi. org/10.1590/0034-7167-2017-0145

24. Bezerra, MFS. Construção e validação de uma cartilha educativa sobre eventos adversos pós-vacinação. Trabalho de conclusão de curso [Graduação em Enfermagem] - Faculdade de Enfermagem Nova Esperança; 2017.

25. Assis SS, Pimenta DN, Schall VT. Materiais impressos sobre dengue: análise crítica e opiniões de profissionais de saúde e educação sobre seu uso. Rev. Bras. Pesq. Educ. Ciênc. 2013;13(3).

26. Oliveira SC, Lopes MVO, Fernandes AFC. Construção e validação de cartilha educativa para alimentação saudável durante a gravidez. Rev. Latino-Am. Enfermagem. 2014;22(4):611-20.

27. Pereira, MG. A sessão de discussão de um artigo cientifico. Rev. Epidemiol. Serv. Saúde, Brasília 2013;22(3):537538. Disponível em:<http://scielo.iec.gov.br/pdf/ess/ v22n3/v22n3a20.pdf. 